\section{Utilización del colgajo de bola adiposa de Bichat para el cierre inmediato de defectos quirúrgicos en el paladar. Reporte de dos casos}

\author{
Use of the Bichat fat ball flap for immediate \\ closure of surgical defects in the palate. \\ Report of two cases
}

\begin{abstract}
Resumen
El objetivo fue describir la utilización del colgajo de bola adiposa de Bichat en el cierre de defectos palatinos inmediato a la resección quirúrgica. Casos clínicos: el caso clínico número 1 (hombre de 60 años) se presentó a la consulta con un aumento de volumen en mucosa del paladar blando, de forma ovoidal, no dolorosa a la palpación, coloración similar de la mucosa del paladar, de $3 \mathrm{~cm}$ de diámetro y de 4 meses de evolución que le incomoda para hablar y alimentarse. El caso clínico número 2 (hombre de 61 ańos) concurre a la consulta con una lesión en maxilar superior a nivel del paladar con diagnóstico patológico de adenoma pleomorfo. En ambos casos, se realizó la resección tumoral y la reconstrucción inmediata mediante el uso de bola adiposa de Bichat. Los defectos fueron cubiertos solamente por el tejido adiposo mencionado, generando una restitución ad integrum de la mucosa oral, evolucionaron favorablemente, sin complicaciones postoperatorias y recuperando la función masticatoria en pocas semanas. El colgajo de bola adiposa de Bichat debe ser considerado una alternativa para reparación de defectos postquirúrgicos gracias a su proximidad, disponibilidad, plasticidad y excelente vascularización, evitando así posibles secuelas relacionadas a la cicatrización secundaria.
\end{abstract}

Palabras clave: Tejido adiposo; Cirugía reconstructiva; Colgajos quirúrgicos; Defectos; Cicatrización de herida (fuente: DeCS BIREME).

\begin{abstract}
The objective was to describe the use of the Bichat fat ball flap in the closure of palatal defects immediately after surgical resection. Clinical cases: clinical case number 1 (60-year-old man) presented to the consultation with an increase in volume of the soft palate mucosa, ovoid in shape, not painful on palpation, similar coloration of the palate mucosa, of $3 \mathrm{~cm}$ in diameter and 4 months of evolution that makes it uncomfortable to talk and feed. Clinical case number 2 (a 61-year-old man) attended the consultation with a lesion in the upper jaw at the level of the palate with a pathological diagnosis of pleomorphic adenoma. In both cases, tumor resection and immediate reconstruction were performed using a Bichat fat ball. The defects were covered only
\end{abstract}

\section{Caso Clínico}

Ezequiel Matías Hilber 1,2,a, Matías García Blanco 1,b Carlos Lazarte 1,2,a, Victoria Santucci 1,2,a, Sebastián Ariel Puia 1,a

${ }^{1}$ Universidad de Buenos Aires, Facultad de Odontología, Cátedra de Cirugía y Traumatología BMF I, Buenos Aires, Argentina.

${ }^{2}$ Hospital Municipal Eva Perón, Servicio de CTBM,

Buenos Aires, Argentina.

a Odontólogo. Especialista en Cirugía y Traumatología

Bucomaxilofacial.

${ }^{\mathrm{b}}$ Odontólogo. Especialista en Prótesis Dentobucomaxilar.

\section{Correspondencia:}

Ezequiel Matías Hilber: ezehilber2@gmail.com Dirección de correspondencia: M. T. de Alvear 2142, CP 1125, Buenos Aires, Argentina.

ORCID: 0000-0001-6810-2191

Coautores:

Matías García Blanco: matias.garciablanco@odontologia. uba.ar

ORCID: 0000-0003-3974-8756

Carlos Lazarte: carloslazarte75@hotmail.com

ORCID: 0000-0002-4123-2532

Victoria Santucci: vicky.santucci@gmail.com

ORCID: 0000-0003-0891-204X

Sebastian Ariel Puia: sebastian.puia@odontologia.uba.ar ORCID: 0000-0002-8480-9071

\section{Editor:}

Juan Carlos Cuevas-González

Universidad Autónoma de Ciudad Juárez, México.

Conflicto de intereses: los autores declaran no tener conflictos de interés.

Fuente de financiamiento: Subsidio FOUBA 330/19-01 e integrantes del SUyOP y Cátedras de Cirugía Bucomaxilofacial 1 y Anatomía Patológica de la Facultad de Odontología de la Universidad de Buenos Aires, Argentina.

Recibido: 01/11/20 Aceptado: $15 / 05 / 21$

Publicado: 05/10/21

( ) Los autores. Este artículo es publicado por la revista Odontología Sanmarquina de la Facultad de Odontología, Universidad Nacional Mayor de San Marcos. Este es un artículo de acceso abierto, distribuido bajo los términos de la licencia Creative Commons Atribución 4.0 Internacional (CC BY 4.0) [https://creativecommons.org/ licenses/by/4.0/deed.es] que permite el uso, distribución y reproducción en cualquier medio, siempre que la obra original sea debidamente citada de su fuente original. 
by the adipose tissue mentioned, generating a restitution ad integrum of the oral mucosa, they evolved favorably, without postoperative complications and recovering the masticatory function in a few weeks. The Bichat adipose ball flap should be considered an alternative for the repair of postsurgical defects thanks to its proximity, availability, plasticity and excellent vascularization, thus avoiding possible sequelae related to secondary healing.

Keywords: Adipose tissue; Reconstructive surgery; Surgical flaps; Defects; Wound healing (source: MeSH NLM).

\section{Introducción}

La patología de origen odontogénico (abscesos, quistes y tumores), defectos quirúrgicos de cirugías resectivas de tumores malignos, traumatismos e incluso lesiones iatrogénicas durante la segmentación del maxilar en cirugía ortognática, pueden llevar a la pérdida de integridad de la mucosa palatina y convertirse en una carga importante para la calidad de vida del paciente y un desafío quirúrgico para el cirujano tratante al tratar estos defectos ${ }^{1}$.

La reconstrucción en cirugía maxilofacial comprende un abanico de alternativas a la hora de planificar el tratamiento de defectos intraorales postquirúrgicos ${ }^{2}$.

La pérdida de sustancia en sectores de la cavidad oral requiere el cierre con tejido vascularizado para evitar la retracción de los tejidos y limitación de ciertas funciones como la apertura bucal, masticación y fonación ${ }^{3}$.

Clasificando según su tamaño, los pequeños defectos cierran mediante la aproximación de los cabos de la herida, mientras para los defectos medianos del área maxilofacial es necesario su reconstrucción por medio de colgajos locales tales como, mucosa del paladar, bola adiposa de Bichat, galea temporoparietal y musculo temporal ${ }^{4,5}$. En referencia a grandes defectos, los colgajos regionales vascularizados o colgajos libres microvascularizados son los preferidos para su reconstrucción ${ }^{6}$.

Durante los últimos años, una gran cantidad de estudios clínicos con un número progresivamente mayor de casos han declarado al colgajo de bola adiposa de Bichat $(\mathrm{BAB})$ idóneo para la reconstrucción de pequeños y medianos defectos que no permitan el cierre primario, incluyendo aquellos originados a partir de resecciones quirúrgicas de tumores benignos como malignos ${ }^{5}$. La utilización de dicho colgajo se basa en su versatilidad, proximidad al defecto, accesibilidad y plasticidad en su manejo respecto a otros colgajos locales ${ }^{7}$. El colgajo de BAB fue detallado por primera vez en 1802 por Bichat y recién en 1986 Tideman publicó una descripción detallada de su anatomía y técnica quirúrgica ${ }^{8}$. Su consistencia se basa en grasa (aproximadamente $10 \mathrm{ml}$ en volumen), cuya función es actuar como almohadilla durante los movimientos de la masticación disminuyendo la fricción. Es resistente a la lipólisis, incluso en casos de pérdida de peso corporal ${ }^{9}$. La BAB está limitada por la fosa pterigomaxilar medialmente y músculos maseteros como buccinadores lateralmente ${ }^{10}$. Se divide anatómicamente en un istmo y 4 prolongaciones: bucal, pterigoidea, temporal superficial y temporal profunda, aportando un tejido de extenso volumen ${ }^{11,12}$. Otro punto importante para destacar es su irrigación vascular comprendida por: rama bucal de la arteria maxilar interna, rama transversa de la cara proveniente de la arteria temporal superficial como también pequeñas ramas de la arteria facial, ofreciendo un aporte vascular múltiple y rico en comparación con otros colgajos ${ }^{11}$.

El objetivo de esta publicación fue describir la utilización del colgajo de bola adiposa de Bichat en el cierre de defectos palatinos inmediato a la resección quirúrgica, con la presentación de casos clínicos.

\section{Reporte de casos}

Se presentan dos casos que fueron tratados en conjunto con los servicios de Cirugía y Traumatología Bucomaxilofacial (CTBMF) I de la Facultad de Odontología de la Universidad de Buenos Aires (FOUBA), y el servicio CTBMF del Hospital Eva Perón, Merlo, Buenos Aires, Argentina; ambos en el año 2019.

\section{Caso clínico 1}

El paciente (masculino de 60 años, con hipertensión controlada) concurre en junio de 2019 manifestando tener un tumor localizado en el paladar. El examen clínico reveló un aumento de volumen en mucosa del paladar blando, de base pediculada, forma ovoidal, no dolorosa a la palpación, consistencia duro-elástica, coloración similar de la mucosa del paladar, de $3 \mathrm{~cm}$ de diámetro y de 4 meses de evolución. El paciente nos refiere la incomodidad que le genera ese tumor al habla y a la masticación. Se realizó una tomografía computada de macizo craneofacial donde se puede observar ausencia de compromiso de los huesos del paladar y fosas nasales (Figura 1). A través del análisis clínico y por imágenes se planificó una biopsia excisional de la lesión bajo anestesia general resecando la misma y reconstruyendo de forma inmediata el defecto remanente con tejido proveniente de la bola adiposa de Bichat, suturándola sin tensión a los bordes del defecto (Figura 2). El paciente evoluciono sin complicaciones postoperatorias con una cicatrización favorable gracias a la metaplasia de la bola adiposa generando una restitución ad integrum de la mucosa oral (Figura 3). El diagnóstico anatomopatológico arrojó el resultado de ".adenoma pleomorfo.. El paciente continúa en control. 


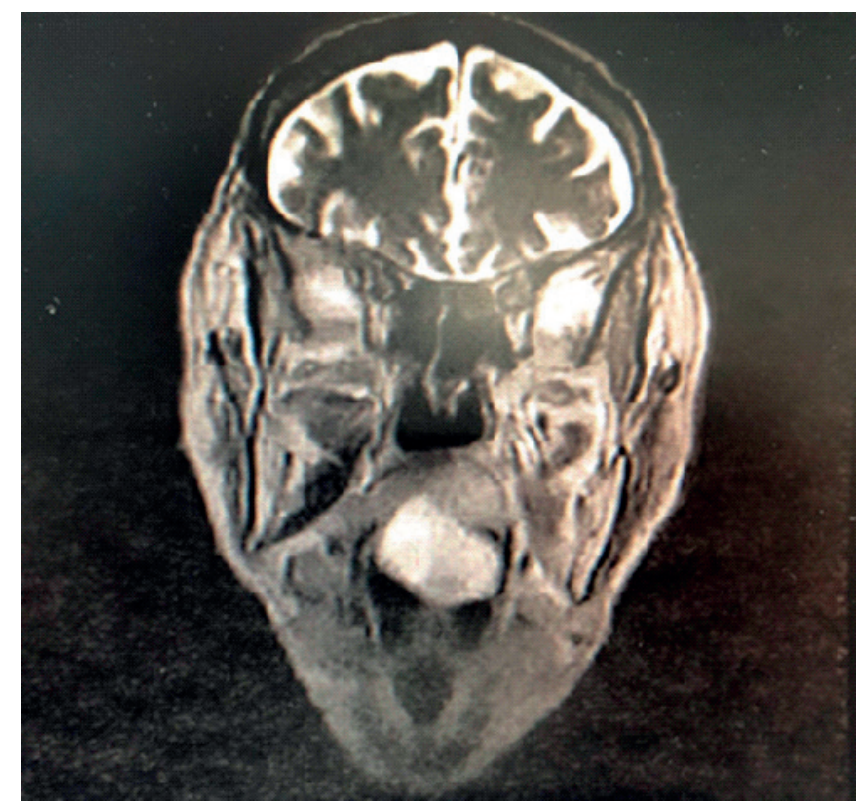

Figura 1. Resonancia magnética de cerebro, macizo craneofacial y mandíbula. Corte coronal, donde se puede observar una imagen hiperintensa en la región palatina compatible con la lesión en cuestión

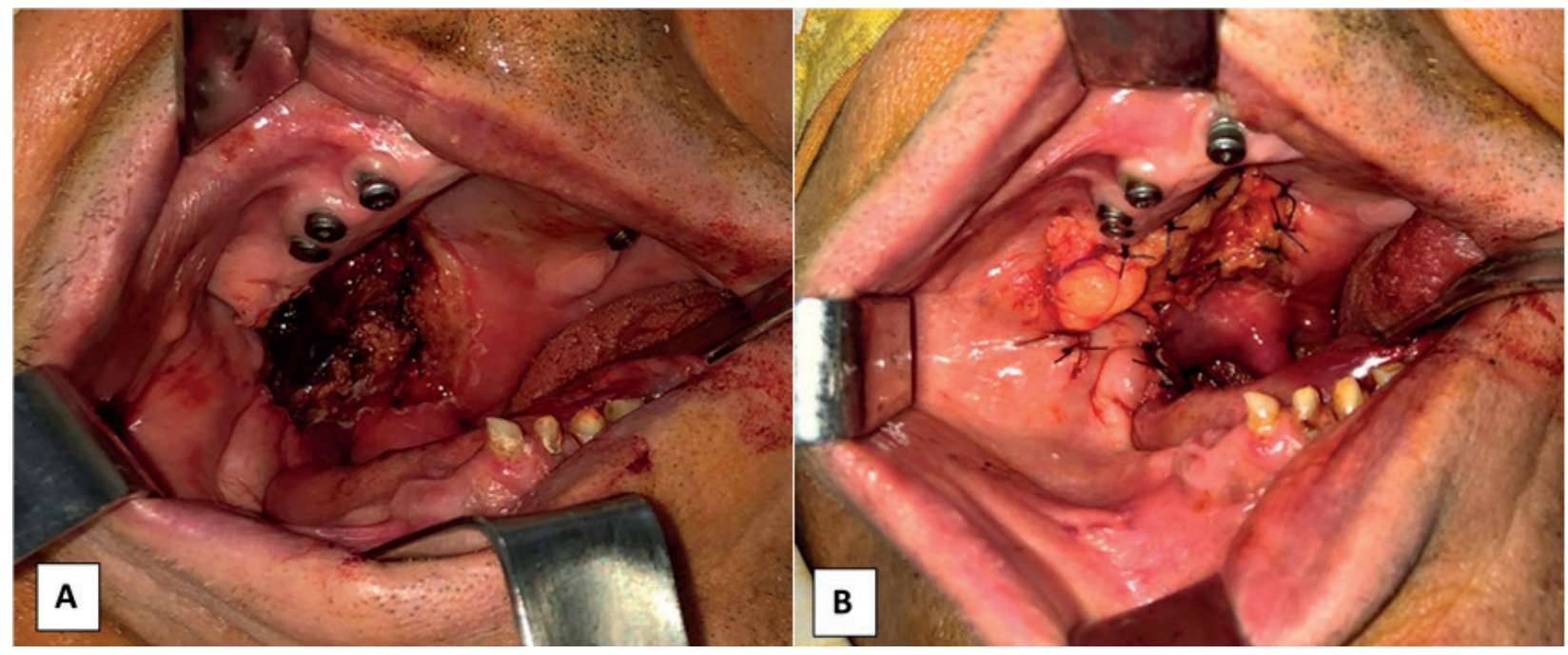

Figura 2. A. Imagen intraoperatoria inmediata a la resección de la lesión palatina. B. Intraoperatoria donde se observa la reconstrucción del defecto con bola adiposa de Bichat

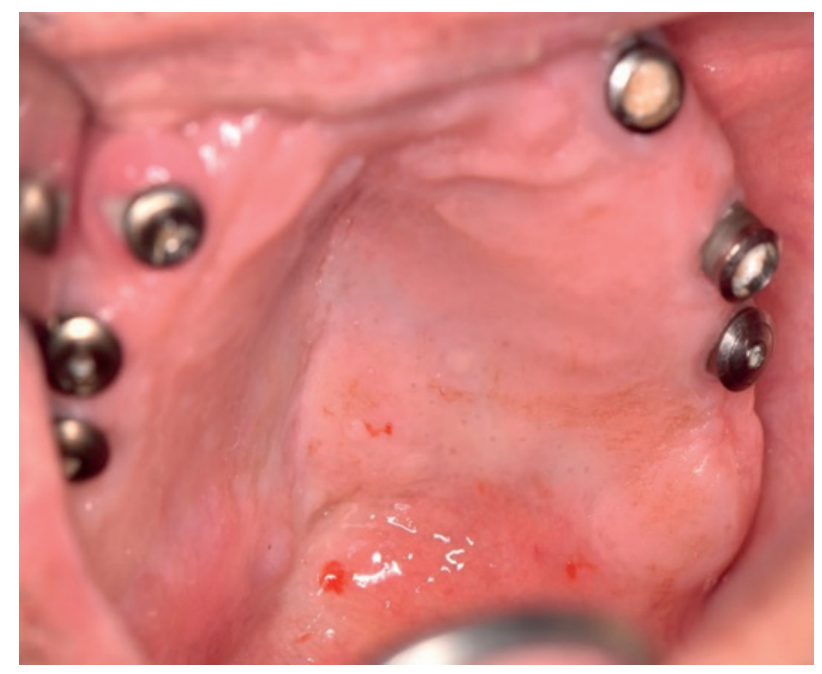

Figura 3. Control postoperatorio, donde se observa la restitución ad integrum de la mucosa oral 


\section{Caso clínico 2}

El paciente (masculino de 61 años, exfumador, hipertenso) concurre al servicio en septiembre de 2019 con un resultado definitivo de "adenoma pleomorfo" correspondiente a una biopsia del maxilar superior previamente realizada en la catedra de CTBMF I de la facultad de odontología U.B.A.

$\mathrm{Al}$ examen clínico presenta un aumento de volumen en maxilar superior, a nivel de la línea media de mucosa del paladar duro y blando, de consistencia duro-elástico, de color rosa pálido, levemente doloroso a la palpación, de $2 \mathrm{~cm}$ de diámetro (Figura 4). Se solicita una tomografía computada de macizo craneofacial donde se puede observar que tanto el hueso maxilar y palatino se encuentran indemnes sin reabsorción ósea (Figura 5). A partir del análisis clínico y por imágenes del paciente, bajo anestesia general y por medio de un abordaje intraoral se realiza la resección del tumor con márgenes quirúrgicos, incluida la mucosa del revestimiento oral para reducir las posibilidades de recurrencia y el cierre inmediato mediante un colgajo de bola adiposa de Bichat (Figura 6). La evolución de la cirugía fue favorable, no se observaron fenestraciones, ni infección de la herida, solo un defecto de tejido blando (Figura 7). Al tiempo se observó la restitución ad integrum de los tejidos.

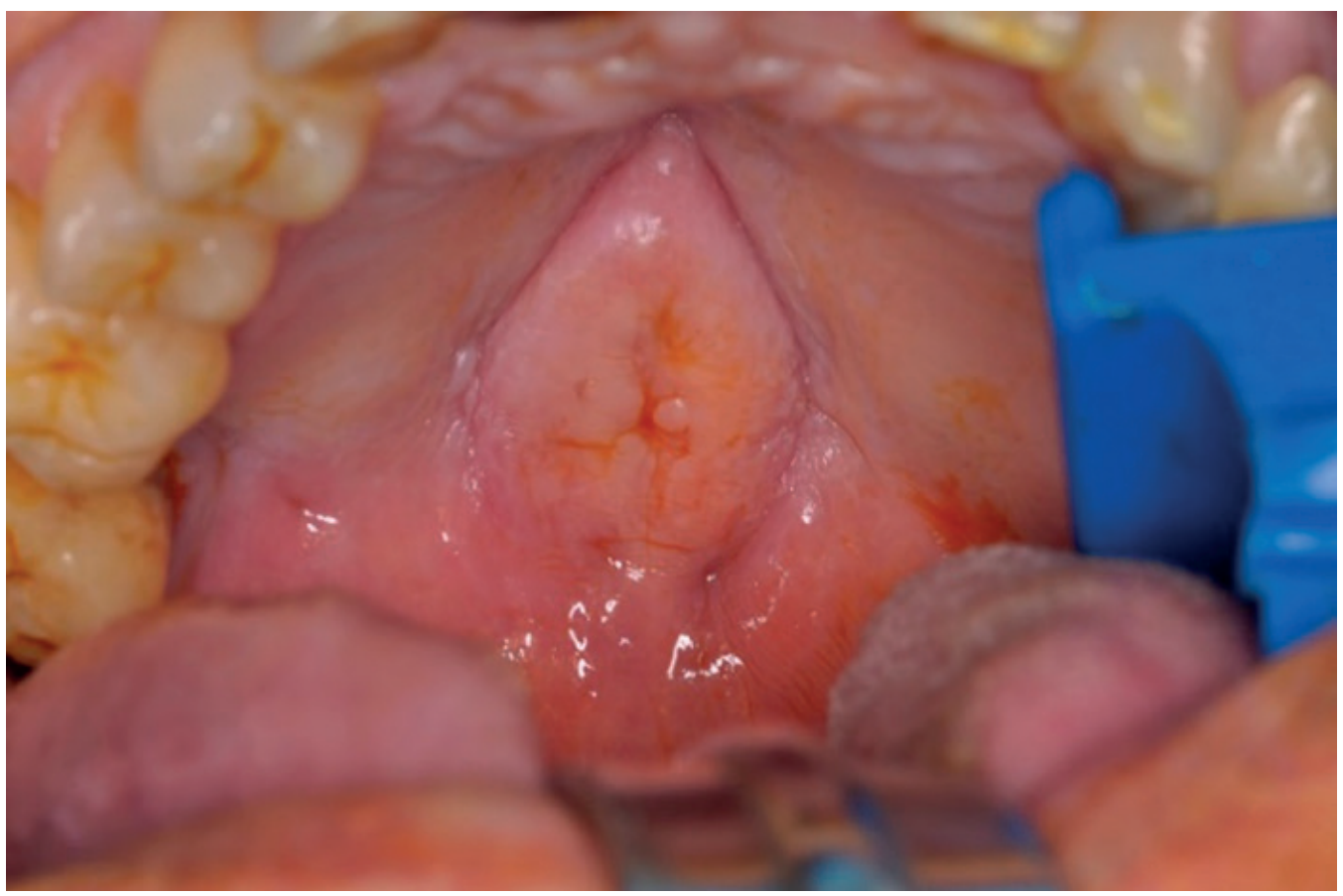

Figura 4. Imagen preoperatoria de la lesión palatina

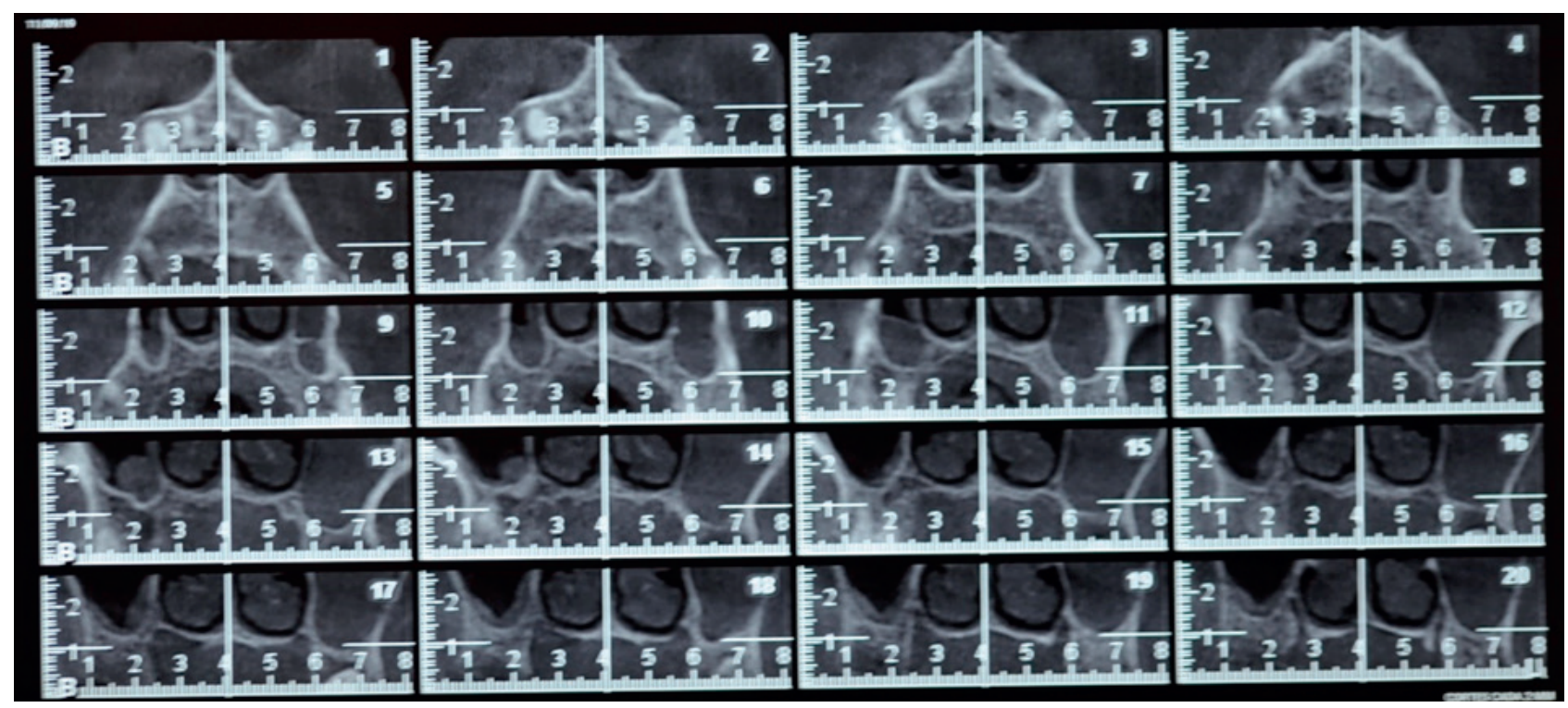

Figura 5. Tomografía computada de macizo craneofacial donde se puede observar la inexistencia de compromiso óseo 


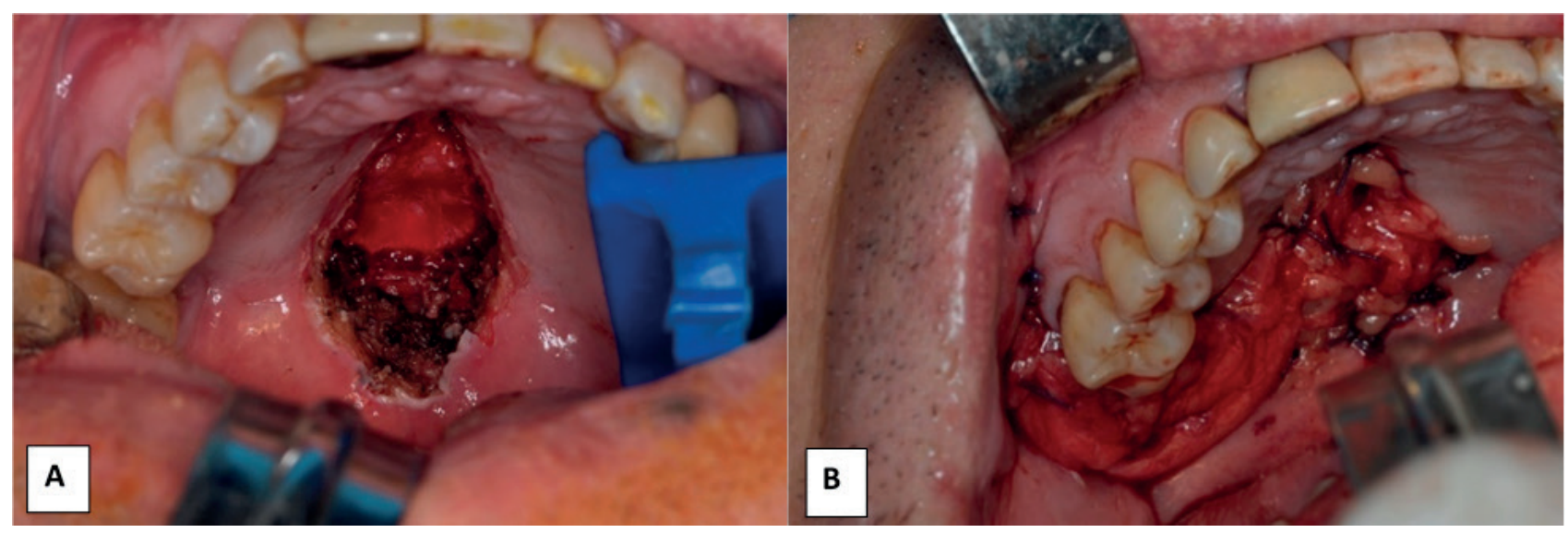

Figura 6. A. Imagen intraoperatoria de la resección de la lesión palatina. B. Imagen intraoperatoria de la reconstrucción del defecto palatino mediante bola adiposa de Bichat

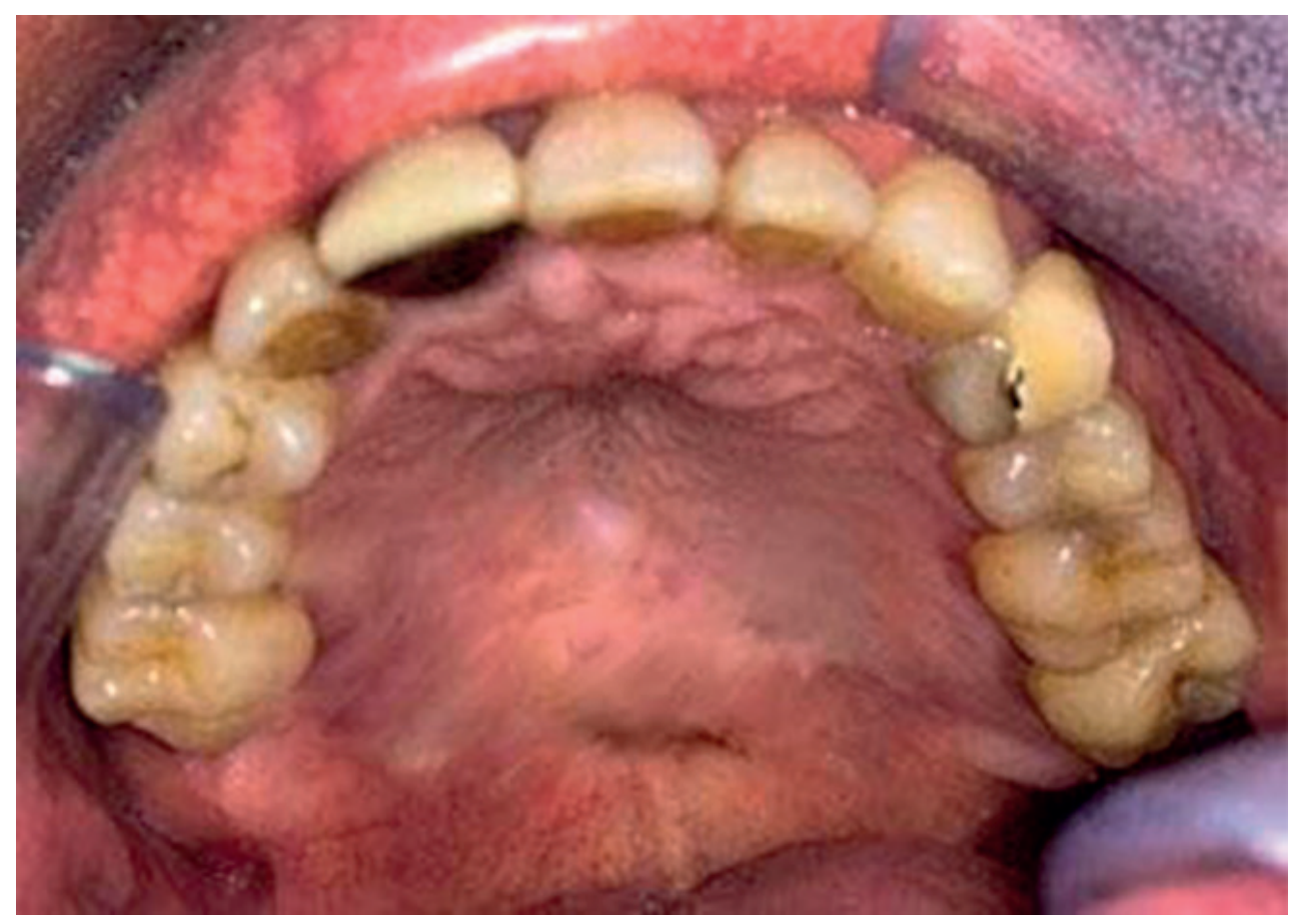

Figura 7. Control postoperatorio, donde se observa la restitución ad integrum de la mucosa oral

\section{Discusión}

Se han descrito varios métodos para cierre de defectos en el paladar. Las técnicas varían desde el cierre primario hasta el secundario, cicatrizando de acuerdo con el grosor del tejido blando restante y la presencia de hueso sano. Si los tejidos residuales tienen hueso sano y el tamaño del defecto es hasta $5 \mathrm{~cm}$, se puede permitir que el área experimente una cicatrización secundaria cubriendo el defecto con una gasa embebida en antiséptico. Cuando el tamaño del defecto es de 5 a $10 \mathrm{~cm}$ se puede reconstruir mediante colgajos locales o loco-regionales incluyendo el colgajo temporoparietal, lingual y bola adiposa de Bichat. Para los defectos mayores de $10 \mathrm{~cm}$ se pueden utilizar colgajos libres microvascularizados para la reconstrucción del área. Una prótesis obturatriz también puede ser una alternativa para cerrar los defectos del hueso palatino sin cirugía. En ambos casos, se prefirió la $\mathrm{BAB}$ para la reconstrucción del defecto palatino debido a su rico suministro sanguíneo y proximidad al sitio quirúrgico evitando mínimas limitaciones funcionales y estéticas ${ }^{13}$.

La primera aplicación clínica de BAB consistió en el cierre de un defecto producto de la resección de un tumor en el paladar, colocando sobre el tejido adiposo un injerto de piel ${ }^{14}$.

Las heridas intraorales tienen ciertas características únicas en comparación con otros sitios, el tejido blando que recubre el hueso alveolar es relativamente delgado y no existe capa de tejido adiposo por debajo de la encía. Por lo tanto, el injerto de piel vascularizado es demasiado voluminoso en la mayoría de los casos y el color del injerto de piel no coincide con el de la mucosa oral ${ }^{15}$. 
El injerto de mucosa libre del paladar tiene un grosor similar a la encía, sin embargo, posee un color más pálido y el volumen de la mucosa palatina que aporta para la reconstrucción es limitado ${ }^{3}$.

La BAB se disecciona y moviliza adecuadamente, es un colgajo delgado y flexible que puede proporcionar un pedículo largo y ancho cuyo diámetro máximo podría alcanzar hasta $7 \mathrm{~cm}$ de tejido transferido 5 . Por estos motivos y la rápida cicatrización se decidió utilizar la $\mathrm{BAB}$ como alternativa reconstructiva en ambos pacientes.

Existe evidencia de la presencia de células madre a partir de la bolsa adiposa de Bichat, siendo grandes promotoras que fomentan una metaplasia del tejido, convirtiéndolo en tejido fibroso y superficialmente en epitelio tan sólo en cinco semanas ${ }^{16,17}$.

También existen publicaciones que sugieren el uso de modelos tridimensionales reabsorbibles sembrados con células madre derivadas de la BAB y diferenciadas a células osteogénicas cuando el defecto quirúrgico incluye al hueso palatino ${ }^{18}$.

La morbilidad del sitio donante mediante la utilización del colgajo de $\mathrm{BAB}$ es baja, siendo una alternativa para el cierre de defectos palatinos. De acuerdo con la revisión de la literatura, el colgajo de $\mathrm{BAB}$ es preferible para la reconstrucción del paladar que el colgajo de buccinador o el colgajo musculo-mucoso de la arteria facial de base superior ${ }^{19,20}$.

Para la reconstrucción de ciertos defectos tumorales, se requiere gran volumen de tejido adiposo y dado que la función de la bola adiposa de Bichat es lubricar los músculos durante su contracción, la pérdida de ese tejido puede inducir la adhesión de estos. Por lo tanto, se recomienda el ejercicio activo de apertura de la boca para los pacientes posterior a la cirugía ${ }^{21}$.

$\mathrm{La} B A B$ tiene una resistencia a la radioterapia y a la contracción tisular posterior a la radiación. Por lo tanto, los cirujanos tienden a utilizar la almohadilla de grasa bucal en pacientes que pueden llegar a recibir radioterapia en el futuro, por lo que convierten a este colgajo una de las alternativas más convenientes para reconstrucciones inmediatas incluso en cirugías de tumores malignos ${ }^{22}$.

En conclusión, el colgajo de bola adiposa de Bichat debe ser considerado una alternativa para la reparación de defectos postquirúrgicos por su excelente irrigación, baja morbilidad del sitio donante y gracias a su proximidad, fácil disponibilidad y plasticidad en comparación con otros colgajos, permitiendo así evitar posibles secuelas relacionadas a la cicatrización por segunda intención.

\section{Referencias bibliográficas}

1. Kablan F. The use of buccal fat pad free graft in closure of soft-tissue defects and dehiscence in the hard palate. Ann Maxillofac Surg. 2016;6(2):241-245. DOI:10.4103/2231-0746.200326

2. Sumarroca A, Rodríguez-Bauzà E, Vega C, Fernández M, Masià J, Quer M, León X. Reconstruction of oral cavity defects with FAMM (facial artery musculomucosal) flaps. Our experience. Acta Otorrinolaringol Esp. 2015; 66(5):275-80. DOI: 10.1016 / j.otorri.2014.10.003

3. Kim MK, Han W, Kim SG. The use of the buccal fat pad flap for oral reconstruction. Maxillofac Plast Reconstr Surg. 2017;25;39(1):5. DOI: 10.1186 / s40902-0170105-5

4. Oliveira Neto JQ, Cetira Filho EL, Andrade GS, Silveira DXD, Carvalho ACGS. Technique of the Buccal Fat Pad Flap as an Alternative for the Surgical Defect of Pleomorphic Adenoma. J Craniofac Surg. 2019;30(3):798-799. DOI: 10.1097 / SCS.0000000000004890

5. Mannelli G, Arcuri F, Comini LV, Valente D, Spinelli G. Buccal Fat Pad: Report of 24 Cases and Literature Review of 1,635 Cases of Oral Defect Reconstruction. ORL J Otorhinolaryngol Relat Spec. 2019;81(1):24-35. DOI: 10.1159 / 000494027

6. Al-Dam A, Zrnc TA, Hanken H, Riecke B, Eichhorn W, Nourwali I, Smeets R, Blessmann M, Heiland M, Gröbe A. Outcome of microvascular free flaps in a high-volume training centre. J Craniomaxillofac Surg. 2014;42(7):1178-83. DOI: 10.1016 / j.jcms.2014.02.005

7. Lagier A, Alshawareb F, Layoun W, Lagier J.P. Le corps gras de la joue dans la reconstruction des pertes de substance postérieure de la cavité buccale. Rev stomatol chir maxillofac. 2010;111(3):152-154. DOI: 10.1016/j.stomax.2009.04.005

8. Tideman H, Bosanquet A, Scott J. Use of the buccal fat pad as a pedicled graft. J Oral Maxillofac Surg.1986; 44(6):435-40. DOI: 10.1016 / s0278-2391 (86) 80007-6

9. Candamourty R, Jain MK, Sankar K, Babu MR. Double-layered closure of oroantral fistula using buccal fat pad and buccal advancement flap. J Nat Sci Biol Med. 2012; 3(2):203-5. DOI: 10.4103 / 0976-9668.101930

10. Arce K. Buccal fat pad in maxillary reconstruction. Atlas Oral Maxillofac Surg Clin North Am. 2007;15(1):2332. DOI: $10.1016 /$ j.cxom.2006.11.003

11. Singh J, Prasad K, Lalitha RM, Ranganath K. Buccal pad of fat and its applications in oral and maxillofacial surgery: a review of published literature (February) 2004 to (July) 2009. Oral Surg Oral Med Oral Pathol Oral Radiol Endod. 2010;110(6):698-705. DOI: 10.1016 / j.tripleo.2010.03.017

12. Zhang HM, Yan YP, Qi KM, Wang JQ, Liu ZF. Anatomical structure of the buccal fat pad and its clinical adaptations. Plast Reconstr Surg. 2002;109(7):250918; discussion 2519-20 DOI: 10.1097 / 00006534200206000-00052

13. Koç O, Tüz HH, Tosun E. A Novel Use of Buccal Fat Pad Flap for Immediate Reconstruction of Palatal Tumor Resection Defect. J Craniofac Surg. 2019; 30 (7): e593-e595. DOI: 10.1097 / SCS.0000000000005593.

14. Egyedi P. Utilization of the buccal fat pad for closure of oro-antral and/or oro-nasal communications. J Maxillofac Surg. 1977;5(4):241-4. DOI: 10.1016/ s0301-0503 (77) $80117-3$

15. Soutar DS, Scheker LR, Tanner NS, McGregor IA. The radial forearm flap: a versatile method for intra-oral 
reconstruction. Br J Plast Surg. 1983;36(1):1-8. DOI $10.1016 / 0007-1226$ (83) 90002-4

16. Farré-Guasch E, Martí-Pagè C, Hernádez-Alfaro F, Klein-Nulend J, Casals N. Buccal fat pad, an oral access source of human adipose stem cells with potential for osteochondral tissue engineering: an in vitro study. Tissue Eng Part C Methods. 2010;16(5):1083-94. DOI: 10.1089 / ten.TEC.2009.0487

17. Salehi-Nik N, Rezai Rad M, Kheiri L, Nazeman P, Nadjmi N, Khojasteh A. Buccal Fat Pad as a Potential Source of Stem Cells for Bone Regeneration: A Literature Review. Stem Cells Int. 2017;2017:8354640. DOI:10.1155/2017/8354640.

18. Conejero JA, Lee JA, Parrett BM, et al. Repair of palatal bone defects using osteogenically differentiated fat-derived stem cells. Plast Reconstr Surg. 2006;117(3):857-863. DOI: 10.1097 / 01.prs.0000204566.13979.c1
19. Van Lierop AC, Fagan JJ. Buccinator myomucosal flap: clinical results and review of anatomy, surgical technique and applications. J Laryngol Otol. 2008;122(2):181187. DOI: 10.1017 / S0022215107008353

20. Berania I, Lavigne F, Rahal A, Ayad T. Superiorly based facial artery musculomucosal flap: A versatile pedicled flap. Head Neck. 2018;40(2):402-405. DOI: 10.1002 / hed.24997

21. Colella G, Tartaro G, Giudice A. The buccal fat pad in oral reconstruction. Br J Plast Surg. 2004 Jun;57(4):3269. DOI: $10.1016 /$ j.bjps.2004.02.005

22. Chakrabarti J, Tekriwal R, Ganguli A, Ghosh S, Mishra PK. Pedicled buccal fat pad flap for intraoral malignant defects: A series of 29 cases. Indian J Plast Surg. 2009;42(1):36-42. DOI: 10.4103 / 0970-0358.53010 